\title{
Preoperative Serum Krebs Von Den Lungen-6 and Surfactant Protein-D Levels in Non-Small Cell Lung Cancer Patients with Interstitial Pneumonia
}

\author{
Masaki Tomita $^{1 *}$, Takanori Ayabe ${ }^{1}$, Eiichi Chosa1, Takashi Asada1, Kazuyo Tsuchiya1, \\ Kunihide Nakamura² \\ ${ }^{1}$ Department of Thoracic and Breast Surgery, Faculty of Medicine, University of Miyazaki, Miyazaki, Japan \\ ${ }^{2}$ Department of Cardiovascular Surgery, Faculty of Medicine, University of Miyazaki, Miyazaki, Japan \\ Email: *mtomita@med.miyazaki-u.ac.jp
}

How to cite this paper: Tomita, M., Ayabe, T., Chosa, E., Asada, T., Tsuchiya, K. and Nakamura, K. (2017) Preoperative Serum Krebs Von Den Lungen-6 and Surfactant Protein-D Levels in Non-Small Cell Lung Cancer Patients with Interstitial Pneumonia. Open Journal of Thoracic Surgery, 7, 1-7.

https://doi.org/10.4236/ojts.2017.71001

Received: January 31, 2017

Accepted: February 26, 2017

Published: March 1, 2017

Copyright $\odot 2017$ by authors and Scientific Research Publishing Inc. This work is licensed under the Creative Commons Attribution International License (CC BY 4.0).

http://creativecommons.org/licenses/by/4.0/

\begin{abstract}
We retrospectively analyzed the prognostic significance of preoperative serum Krebs von den Lungen-6 (KL-6) surfactant protein-D (SP-D) levels in non-small cell lung cancer (NSCLC) patients with interstitial pneumonia (IP). We enrolled 41 NSCLC patients with IP who have undergone curative surgery. Prognostic significance of serum KL-6 and SP-D levels was examined. We found a significant relationship between serum KL-6 and SP-D levels in NSCLC patients with IP. However, the 5-year survival of patients with high serum KL-6 level was poor, whereas serum SP-D level was not related to patients' survival. Univariate analysis revealed that there was a trend towards an association between serum KL-6 level and patients' prognosis but this did not reach statistical significance. This might be due to small number of study patients. In conclusion, there is a possibility that serum KL-6 level is a prognostic marker regardless of the presence of IP.
\end{abstract}

\section{Keywords}

Non-Small Cell Lung Cancer, Serum KL-6 and SP-D Levels, Interstitial Pneumonia, Prognosis

\section{Introduction}

Krebs von den Lungen-6 (KL-6) is a high-molecular-weight glycoprotein and known to be expressed in regeneration of type II pneumocytes [1] and has been reported to serve as a sensitive serum marker for interstitial pneumonia (IP) and 
is now clinically used to detect the presence of IP [2] [3]. However, KL-6 was originally introduced as a tumor marker for lung cancer [4] and recent studies have implied that KL-6 can serve as a tumor marker [5]. Some previous studies also showed that serum KL-6 level is useful for predicting survival of non-small cell lung cancer (NSCLC) patients who have undergone curative surgery [6] [7].

It has not been known whether NSCLC patients with IP might have higher serum levels of KL-6. To our knowledge, only a few study examined the prognostic significance of serum KL-6 level in NSCLC patients with IP [8] [9]. Miyazaki et al. [8] reported the prognostic significance of serum KL-6 levels in lung cancer patients with or without IP. However, the ratio of IP patients who underwent surgery for NSCLC was only $20.6 \%$ (14/68) in their study population. Our previous study also showed the similar findings [9], but the number of patient with IP was very small (only 14 patients).

Therefore, in the present study, we investigated the prognostic significance of serum KL-6 level in NSCLC patients with IP who underwent curative surgery. We also examined serum surfactant protein-D (SP-D) level which is also used clinically as a marker for IP [10].

\section{Patients and Methods}

This retrospective study had institutional review board approval, and the need to obtain patient consent was waived. Consecutive NSCLC patients with IP who underwent surgery from 2004 to 2014 in our hospital were enrolled into the present retrospective study. The following patients were excluded: 1) patients who had not received complete resection which consisted of either a lobectomy or a pneumonectomy together with the regional lymph nodes dissection, 2) patients who had not examined preoperative serum KL-6 and SP-D levels, 3) patients who died of other diseases including acute exacerbation of IP after surgery, and 4) patients who lost to follow-up. Forty-one consecutive resected NSCLC patients were enrolled into the present retrospective study. The clinicopathologcal factors of patients were shown in Table 1 . The cut-off value of serum KL-6 and SP-D was $500 \mathrm{U} / \mathrm{mL}$ and $110 \mathrm{ng} / \mathrm{mL}$, respectively. The time interval between preoperative serum KL- 6 and SP-D examination and surgical resection was less than 2 weeks in all the patients. IPs were confirmed on the basis of a radiologic finding on the chest CT scan according to the clinical criteria proposed by the Japanese Respiratory Society, and these criteria are consistent with the 2011 guidelines of the American Thoracic Society [11]. Pathological (p) tumor-node-metastasis (TNM) staging was recorded in all patients based on the 7th edition of the American Joint Committee on Cancer (AJCC)/Union for International Cancer Control (UICC) classification. Follow-up information, including cause of death, was ascertained through a review of clinic notes and direct or family contact. The simple linear regression analysis was used for assessing associations between serum KL-6 and SP-D levels. The disease-specific survival curves of the patients were plotted by using the Kaplan-Meier method and 
Table 1. Clinical characteristics.

\begin{tabular}{|c|c|c|}
\hline Factors & & Number of patients \\
\hline \multirow[t]{2}{*}{ Age } & $<65$ & 16 \\
\hline & $\geq 65$ & 25 \\
\hline \multirow[t]{2}{*}{ Gender } & Male & 31 \\
\hline & Female & 10 \\
\hline \multirow[t]{2}{*}{ Smoking } & Never & 8 \\
\hline & Current/Former & 33 \\
\hline \multirow[t]{2}{*}{ Histology } & Adenocarcinoma & 21 \\
\hline & Others & 20 \\
\hline \multirow[t]{2}{*}{$\mathrm{p}$ Stage } & I & 30 \\
\hline & II-III & 11 \\
\hline \multirow[t]{2}{*}{ pT status } & pT1 & 25 \\
\hline & pT2- 3 & 16 \\
\hline \multirow[t]{2}{*}{$\mathrm{pN}$ status } & pN0 & 34 \\
\hline & pN1 - 2 & 7 \\
\hline \multirow[t]{2}{*}{ CEA } & Normal & 21 \\
\hline & High & 20 \\
\hline \multirow[t]{2}{*}{ KL-6 } & Normal & 22 \\
\hline & High & 19 \\
\hline \multirow[t]{2}{*}{ SP-D } & Normal & 21 \\
\hline & High & 20 \\
\hline
\end{tabular}

CEA: carcinoembryonic antigen, KL-6: Krebs von den Lungen-6, SP-D: surfactant protein-D.

analyzed using the log-rank test. The Cox regression hazard model was used for univariate analysis to assess the prognostic value of serum KL-6 and SP-D levels. Statistical calculations were conducted with JMP (SAS Institute Inc., Cary, NC, USA) and values of $p$ less than 0.05 were accepted as being significant.

\section{Results}

There were 19/41 patients with high serum KL-6 level, and 20/41 patients with high serum SP-D level was found. Linear regression analysis showed the significant relationship between serum KL-6 and SP-D value (Figure 1, y $=48.653+$ $0.155 \mathrm{x}, \mathrm{R}^{2}=0.260, p<0.01$ ).

The postoperative disease-specific 5-year survival rates in patients with high serum KL-6 level were poorer. This difference was significant ( $p=0.024$, Figure 2 ). However, serum SP-D level was not related to patients' survival ( $p=0.297$, Figure 3), in spite of the positive relationship between serum KL-6 and SP-D levels.

The result of univariate analysis is summarized in Table 2. The pT status (pT1 vs. pT2 - 3) and serum CEA level (normal vs. high) were related to patients' prognosis, while others were not. The association between serum KL-6 level and patients' prognosis did not reach statistical significance. 


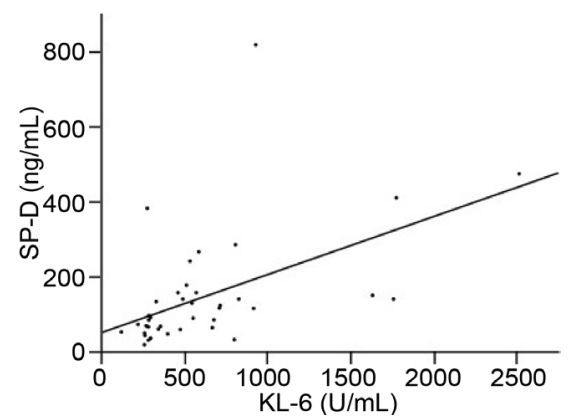

Figure 1. Linear regression analysis showing the relationship between serum KL-6 and SP-D value. $\left(\mathrm{y}=48.653+0.155 \mathrm{x}, \mathrm{R}^{2}=0.260, p<0.01\right)$

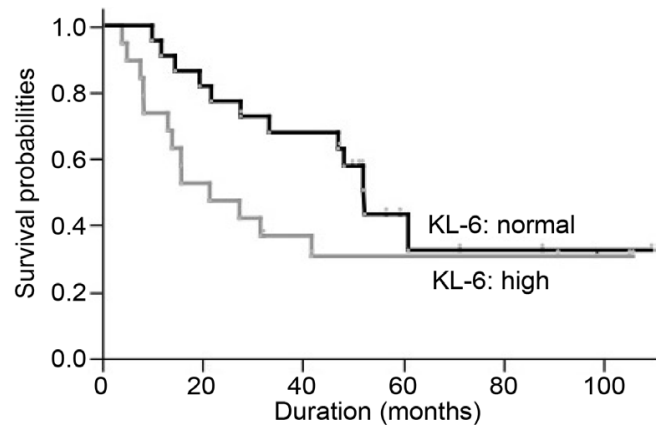

Figure 2. Survival of patients based on serum KL-6 level.

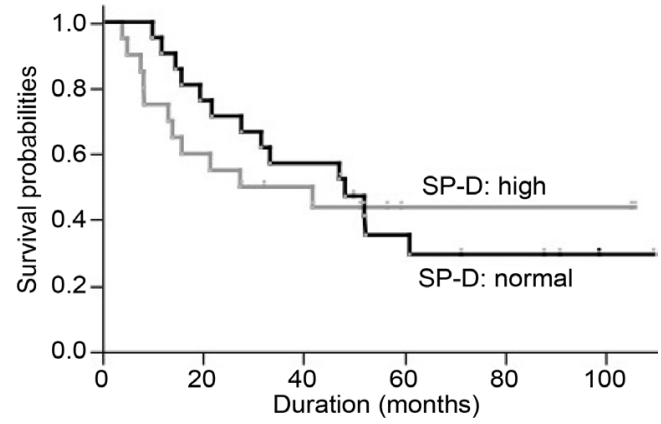

Figure 3. Survival of patients based on serum SP-D level.

Table 2. Univariate analysis.

\begin{tabular}{cccccc}
\hline & Favorable & Unfavorable & Hazard ratio & $95 \%$ CI & $p$ Value \\
\hline Age & $<65$ & $\geq 65$ & 0.52 & $0.203-1207$ & 0.13 \\
Gender & Female & Male & 0.58 & $0.194-1.443$ & 0.26 \\
Smoking & Never & Current/Former & 0.58 & $0.168-1.527$ & 0.29 \\
Histology & Adenocarcinoma & Others & 0.66 & $0.295-1.458$ & 0.31 \\
p Stage & I & II-III & 0.52 & $0.229-1.278$ & 0.15 \\
pT status & pT1 & pT2 - 3 & 0.43 & $0.195-0.970$ & 0.04 \\
pN status & pN0 & pN1 - 2 & 0.51 & $0.205-1.544$ & 0.21 \\
CEA & Normal & High & 0.21 & $0.084-0.486$ & $<0.01$ \\
KL-6 & Normal & High & 0.53 & $0.237-1.181$ & 0.12 \\
SP-D & Normal & High & 0.87 & $0.736-1.973$ & 0.74 \\
\hline
\end{tabular}

CEA: carcinoembryonic antigen, KL-6: Krebs von den Lungen-6, SP-D: surfactant protein-D, CI: Confidence interval. 


\section{Discussion}

Serum KL-6 level is derived from type II pneumocytes and is a well-known serum marker for IP [1]. Elevated serum KL-6 has been observed in patients with IP [2] [3], which might reflect the number of type II pneumocytes increased by damaging the alveolar epithelium. Therefore, serum KL-6 level can be used to monitor activity of IP.

In addition, previous studies showed that serum KL-6 level is an independent prognostic factor in NSCLC patients [6] [7] [8] [9]. The reason why serum KL-6 level can serve as a prognostic biomarker in NSCLC patients who undergo curative surgery has been unknown in detail. KL-6 is classified as a MUC1 mucin [12] and previous studies showed a significant relationship between MUC1 expression and patients' survival [13] [14]. Therefore, serum KL-6 level might reflect the degree of tumor aggressiveness, resulting poor survival.

Taken together, serum KL-6 level can serve as a marker of activity of IP as well as a prognostic biomarker for NSCLC. Therefore, the evaluation of serum KL-6 level in NSCLC patients with IP is difficult. When NSCLC patients with IP have high serum KL-6 level, it is difficult to distinguish whether high serum KL-6 level means as a IP marker or a tumor marker. Therefore, we examined the serum KL-6 level in NSCLC patients with IP. In the present study, we showed that there was a significant relationship between serum KL-6 and SP-D levels in NSCLC patients with IP. Since all our study patients have IP, this result was easy to understand.

We also found that the 5-year survival of patients with high serum KL-6 level was poor, whereas serum SP-D level was not related to patients' survival. From this result, it can be considered that serum KL-6 level can serve as a marker of activity of IP as well as a prognostic biomarker for NSCLC but SP-D might serve as a marker for IP only.

However, in univariate analysis, there was a trend towards an association between serum KL-6 level and patients' prognosis but this did not reach statistical significance in NSCLC patients with IP. We believe that this might be due to small number of patients. Therefore, there is a possibility that serum KL-6 level is a prognostic marker regardless of the presence of IP. As commented above, there were some limitations in the present study. The study was retrospective and the number of patients with high serum KL-6 level was small. However, we showed a clear tendency of the association between KL- 6 and patients' prognosis in NSCLC patients with IP. We believe that this result is meaningful. Therefore, a large cohort study will be required to confirm our results.

\section{Conclusion}

In conclusion, there is a possibility that serum KL-6 level is a prognostic marker for NSCLC patients regardless of the presence of IP.

\section{Conflict of Interest}

The authors have declared that no conflict of interest exists. 


\section{References}

[1] Hirasawa, Y., Kohno, N., Yokoyama, A., Inoue, Y., Abe, M. and Hiwada, K. (1997) KL-6, a Human MUC1 Mucin, Is Chemotactic for Human Fibroblasts. American Journal of Respiratory Cell and Molecular Biology, 17, 501-507. https://doi.org/10.1165/ajrcmb.17.4.2253

[2] Kohno, N., Kyoizumi, S., Awaya, Y., Fukuhara, H., Yamakido, M. and Akiyama, M. (1989) New Serum Indicator of Interstitial Pneumonitis Activity. Sialylated Carbohydrate Antigen KL-6. Chest, 96, 68-73. https://doi.org/10.1378/chest.96.1.68

[3] Kohno, N., Awaya, Y., Oyama, T., Yamakido, M., Akiyama, M., Inoue, Y., Yokoyama, A., Hamada, H., Fujioka, S. and Hiwada, K. (1993) KL-6, a Mucin-Like Glycoprotein, in Bronchoalveolar Lavage Fluid from Patients with Interstitial Lung Disease. The American Review of Respiratory Disease, 148, 637-642. https://doi.org/10.1164/ajrccm/148.3.637

[4] Kohno, N., Akiyama, M., Kyoizumi, S., Hakoda, M., Kobuke, K. and Yamakido, M. (1988) Detection of Soluble Tumor-Associated Antigens in Sera and Effusions Using Novel Monoclonal Antibodies, KL-3 and KL-6, against Lung Adenocarcinoma. Japanese Journal of Clinical Oncology, 18, 203-216.

[5] Inata, J., Hattori, N., Yokoyama, A., Ohshimo, S., Doi, M., Ishikawa, N., Hamada, H. and Kohno, N. (2007) Circulating KL-6/MUC1 Mucin Carrying Sialyl Lewisa Oligosaccharide Is an Independent Prognostic Factor in Patients with Lung Adenocarcinoma. International Journal of Cancer, 120, 2643-2649. https://doi.org/10.1002/ijc.22613

[6] Shoji, F., Yamazaki, K., Kouso, H., Mori, R. and Takeo, S. (2016) Predictive Impact for Postoperative Recurrence of Preoperative Serum Krebs von den Lungen-6 Concentration in Pathologic Stage IA Non-Small Cell Lung Cancer. The Annals of Thoracic Surgery, 101, 1903-1908. https://doi.org/10.1016/j.athoracsur.2015.11.066

[7] Tanaka, S., Hattori, N., Ishikawa, N., Shoda, H., Takano, A., Nishino, R., Okada, M., Arihiro, K., Inai, K., Hamada, H., Yokoyama, A. and Kohno, N. (2012) Krebs von den Lungen-6 (KL-6) Is a Prognostic Biomarker in Patients with Surgically Resected Nonsmall Cell Lung Cancer. International Journal of Cancer, 130, 377-387. https://doi.org/10.1002/ijc. 26007

[8] Miyazaki, K., Kurishima, K., Kagohashi, K., Kawaguchi, M., Ishikawa, H., Satoh, H. and Hizawa, N. (2010) Serum KL-6 Levels in Lung Cancer Patients with or without Interstitial Lung Disease. Journal of Clinical Laboratory Analysis, 24, 295-299. https://doi.org/10.1002/jcla.20404

[9] Tomita, M., Ayabe, T., Chosa, E., Nose, N. and Nakamura, K. (2016) Prognostic Significance of Preoperative Serum Krebs von den Lungen-6 Level in Non-Small Cell Lung Cancer. General Thoracic and Cardiovascular Surgery, 64, 657-661. https://doi.org/10.1007/s11748-016-0706-4

[10] Takahashi, H., Fujishima, T., Koba, H., Murakami, S., Kurokawa, K., Shibuya, Y., Shiratori, M., Kuroki, Y. and Abe, S. (2000) Serum Surfactant Proteins A and D as Prognostic Factors in Idiopathic Pulmonary Fibrosis and Their Relationship to Disease Extent. American Journal of Respiratory and Critical Care Medicine, 162, 1109-1114. https://doi.org/10.1164/ajrccm.162.3.9910080

[11] Kinoshita, A., Hirose, K., Taniguchi, T., Soda, H., Rikitake, T., Tsurukawa, Y., Kanda, T. and Hara, K. (1990) Lung Cancer Associated with Idiopathic Interstitial Pneumonia. Nihon Kyobu Shikkan Gakkai Zasshi, 28, 852-858. (In Japanese)

[12] Kohno, N., Inoue, Y., Hamada, H., Fujioka, S., Fujino, S., Yokoyama, A., Hiwada, K., Ueda, N. and Akiyama, M. (1994) Difference in Sero-Diagnostic Values among 
KL-6-Associated Mucins Classified as Cluster 9. International Journal of Cancer Supplement, 8, 81-83. https://doi.org/10.1002/ijc.2910570717

[13] Xu, F., Liu, F., Zhao, H., An, G. and Feng, G. (2015) Prognostic Significance of Mucin Antigen MUC1 in Various Human Epithelial Cancers: A Meta-Analysis. Medicine, 94, e2286. https://doi.org/10.1097/MD.0000000000002286

[14] Nagai, S., Takenaka, K., Sonobe, M., Ogawa, E., Wada, H. and Tanaka, F. (2006) A Novel Classification of MUC1 Expression Is Correlated with Tumor Differentiation and Postoperative Prognosis in Non-Small Cell Lung Cancer. Journal of Thoracic Oncology, 1, 46-51.

Submit or recommend next manuscript to SCIRP and we will provide best service for you:

Accepting pre-submission inquiries through Email, Facebook, LinkedIn, Twitter, etc. A wide selection of journals (inclusive of 9 subjects, more than 200 journals) Providing 24-hour high-quality service User-friendly online submission system Fair and swift peer-review system Efficient typesetting and proofreading procedure Display of the result of downloads and visits, as well as the number of cited articles Maximum dissemination of your research work

Submit your manuscript at: http://papersubmission.scirp.org/ Or contact ojts@scirp.org 